\title{
Bone marrow transplantation
}

\author{
B H N Yasmeen ${ }^{1}$
}

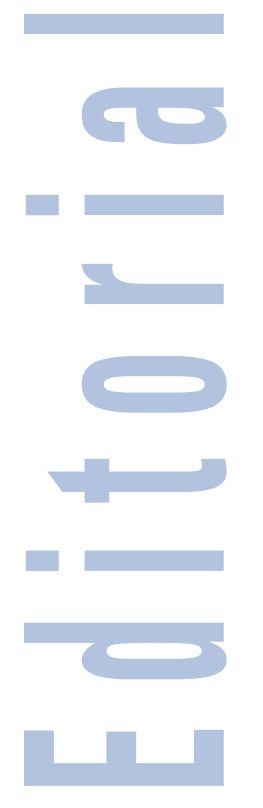

Bone marrow transplantation (BMT) is today a life-saving treatment for many hither to incurable diseases. Over the last two decades, BMT has seen rapid expansion and a constant evolution in technology use. ${ }^{1,2}$ Bone marrow is supplemented as stem cell source by peripheral blood or cord blood, therefore this procedure is described as Hematopoietic Stem Cells Transplantation (HSCT). At the end of 2012, 20.2 million people had registered their willingness to be a bone marrow donor with one of the 67 registries from 49 countries participating in Bone Marrow Donors Worldwide. A further 561,000 cord blood units had been received by one of 46 cord blood units from 30 countries participating. ${ }^{3}$

However, because of the multidisciplinary highlevel support required, there are only a few centers in the developing world which are performing bone marrow transplants. For these reasons fifty-five years after publication of the first hematopoietic stem cell transplantation this technique has started its journey very recently in Bangladesh on October 2013 at Dhaka Medical College Hospital (DMCH).

In 1959 the first European bone marrow transplantion was performed by Georges Mathé, a French oncologist. ${ }^{4}$ Mathé later pioneered the use of bone marrow transplants in the treatment of leukemia. ${ }^{4}$ The first autologous stem cell transplant was undergone by Dr. E. Donnall Thomas in 1957. He received the Medicine Nobel prize in 1990 for the pioneer use of this treatment. ${ }^{5}$ The first physician to perform a successful human bone marrow transplant on a disease other than cancer was Robert A. Good at the University of Minnesota in $1968 .{ }^{6}$ In 1975 , John Kersey, M.D., also of the University of Minnesota, performed the first successful bone marrow transplant to cure lymphoma. ${ }^{7}$ About two decades later BMT introduced in this sub continent. The Tata Memorial Hospital in Bombay initiated the BMT procedure in 1983,for the first time in India. ${ }^{8}$ In Pakistan, first HSCT was started in October 1995 at Dr Ziauddin Hospital. $^{9}$

Hematopoietic stem cell transplantation (HSCT) is the transplantation of multipotent hematopoietic stem cells, usually derived from bone marrow, peripheral blood, amniotic fluid or umbilical cord blood.

Many recipients of HSCTs are multiple myeloma ${ }^{10}$ or leukemia patients. ${ }^{11}$ Candidates for HSCTs include pediatric cases where the patient has an inborn defect such as severe combined immunodeficiency or congenital neutropenia with defective stem cells, and also children or adults with aplastic anemia ${ }^{12}$ who have lost their stem cells after birth. Other conditions $^{13}$ treated with stem cell transplants include sickle-cell disease, myelodysplastic syndrome, neuroblastoma, lymphoma, Ewing's sarcoma, desmoplastic small round cell tumor, chronic granulomatous disease and Hodgkin's disease.

There are different ways of doing HSCT depending on the source of transplanted stem cells.

Autologous HSCT requires the extraction (apheresis) of haematopoietic stem cells (HSC) from the patient and storage of the harvested cells in a freezer. The patient is then treated with high-dose chemotherapy with or without radiotherapy with the intention of eradicating the patient's malignant cell population at the cost of partial or complete bone marrow ablation (destruction of patient's bone marrow function to grow new blood cells). The patient's own stored stem cells are then transfused into his/her bloodstream, where they replace destroyed tissue and resume the patient's normal blood cell production. Autologous transplants have the advantage of lower risk of infection during the immune-compromised portion of the treatment since the recovery of immune function is rapid. Also, the incidence of patients experiencing rejection (graft-versushost disease) is very rare due to the donor and recipient being the same individual

Allogeneic HSCT involves two people: the (healthy) donor and the (patient) recipient. Allogeneic HSC donors must have a tissue (HLA) type that matches the recipient. Matching is performed on the basis of variability at three or more loci of the HLA gene, and a perfect match 
at these loci is preferred. Even if there is a good match at these critical alleles, the recipient will require immunosuppressive medications to mitigate graft-versus-host disease. Allogeneic transplant donors may be related (usually a closely HLA matched sibling), syngeneic (a monozygotic or 'identical' twin of the patient) or unrelated (donor who is not related and found to have very close degree of HLA matching).

A Transplant Process includes three steps- Stem Cell Collection, Conditioning, Stem Cell Infusion \& Engraftment.

Stem Cells are collected from donors blood (in allogenic transplant) by cell separator machine or Bone Marrow aspiration. In Autologous transplant Stem Cells are collected by cell separator machine from patients own blood. Hence, it can be done only after disease has been brought under control by using standard treatment.

Conditioning is the name given to high dose Chemotherapy or Radiotherapy to destroy or suppress patients existing Bone Marrow so that donor Stem Cell can home in Bone Marrow and start functioning.

After conditioning Blood Stem Cells or Bone Marrow are given to the patient through veins, just like Blood Transfusion. These stem cells then reach to Bone Marrow, home there and start producing blood. Time taken for blood production is called engraftment period. Before engraftment patients blood counts are markedly depressed for around 7-10 days, chances of infections are highs so patients are kept in strict isolation rooms. During this time patient will need close monitoring of blood counts and regular blood/platelet transfusions

Average time taken for transplant ranges from 3-4 weeks after that patient is discharged home on oral medications to prevent graft versus host disease and infections. Patients need to be in close regular follow up for first 3- 6 months of transplant and advised to stay near the transplant centre. By the one year post transplant patient's immune system recovers and most of the medicines can be stopped.

Prognosis in HSCT varies widely dependent upon disease type, stage, stem cell source, HLA-matched status (for allogeneic HCST) and conditioning regimen. A transplant offers a chance for cure or long-term remission if the inherent complications of graft versus host disease, immuno-suppressive treatments and the spectrum of opportunistic infections can be survived. ${ }^{14,15}$ In recent years, survival rates have been gradually improving across almost all populations and sub-populations receiving transplants. ${ }^{16}$

A 51 years old man, suffering from multiple myeloma (diagnosed in December 2009) was the first ever patient to have autologus bone marrow transplant in October 2013 at $\mathrm{DMCH}$, Bangladesh. A 25-member team consisting of doctors, nurses, and technicians of which three BMT experts from Massachusetts General Hospital, USA provided assistance as part of a memorandum of understanding penned between the two hospitals. Hope this will be a successful story of BMT in the medical science history of Bangladesh.

\section{References}

1. Daikeler T, Hügle T, Farge D, Andolina M, Gualandi F, Baldomero $H$, et al. Allogeneic hematopoietic SCT for patients with autoimmune diseases. Bone Marrow Transplant. 2009;44(1):27-33. [PubMed]

2. Hirano M, Martí R, Casali C, Tadesse S, Uldrick T, Fine B, et al. Allogeneic stem cell transplantation corrects biochemical derangements in MNGIE. Neurology. 2006;67(8):1458-1460. [PubMed]

3. $\wedge$ Bone Marrow Donors Worldwide Annual Report 2012. http://www.bmdw.org/uploads/media/BMDW2012.pdf

4. ^ Martin, Douglas (20 October 2010). "Dr. Georges Mathé, Transplant Pioneer, Dies at 88". New York Times.

5. Thomas ED, Lochte HL, Lu WC et al. (1957). "Intravenous infusion of bone marrow in patients receiving radiation and chemotherapy". New England Journal of Medicine 157 (11): 491-496. doi:10.1056 / NEJM195709122571102. PMID 13464965.

6. Saxon, Wolfgang (18 June 2003). "Robert A. Good, 81, Founder Of Modern Immunology, Dies". New York Times.

7. $\wedge$ The Bone Marrow Foundation. "Cancer Research Pioneer Dies". Retrieved 6 October 2013.

8. Advani $\mathrm{SH}$,Saikia T. Bone marrow transplantation in India.Indian J Pediatr 1987;54:871-73

9. Shamsi T,Hashmi K, Adil S, Ahmad P, Irfan M, Raza $S$ et al. The stem cell transplant program in Pakistan--the first decade. Bone Marrow Transplant. 2008 Aug;42 Suppl 1:S114-S117. doi: 10.1038/bmt.2008.137.

10. ^ Bladé J, Samson D, Reece D. "Criteria for evaluating disease response and progression in patients with multiple myeloma treated by high-dose therapy and haemopoietic stem cell transplantation. Myeloma Subcommittee of the EBMT. European Group for Blood and Marrow Transplant". Br. J. Haematol. 1998; 102 (5): 1115-23. doi:10.1046/j.1365-2141.1998.00930.x. PMID 9753033.

11. Pavletic SZ, Khouri IF, Haagenson M. "Unrelated donor marrow transplantation for B-cell chronic lymphocytic leukemia after using myeloablative conditioning: results from the Center for International Blood and Marrow Transplant research"J.Clin.Oncol. 2005; 23 (24): 5788-94. doi:10.1200/JCO.2005.03.962. PMID 16043827.

12. ^ Locasciulli A, Oneto $R$, Bacigalupo A."Outcome of patients with acquired aplastic anemia given first line bone marrow transplantation or immunosuppressive treatment in the last decade: a report from the European Group for Blood and Marrow Transplantation (EBMT)". Haematologica 2007; 92 (1): 11-8. doi:10.3324/haematol. 10075. PMID 17229630

13. ^ Center for International Blood and Marrow Transplant Research. "CIBMTR Summary Slides I".

14. ^ Russell N, Bessell E, Stainer C, Haynes A, Das-Gupta E, Byrne J. "Allogenic haemopoietic stem cell transplantation for multiple myeloma or plasma cell leukaemia using fractionated total body radiation and high-dose melphalan conditioning". Acta Oncol. 2000;39 (7): 837-41. doi:10.1080/028418600750063596. PMID 11145442.

15. ^ Nivison-Smith I, Bradstock KF, Dodds AJ, Hawkins PA, Szer J "Haemopoietic stem cell transplantation in Australia and New Zealand, 1992-2001: progress report from the Australasian Bone Marrow Transplant Recipient Registry". Intern Med J. 2005; 35 (1): 18-27. doi:10.1111/j.1445-5994.2004.00704.x. PMID 15667464

16. ^ Data analysis slides by Center for International Blood and Marrow Transplant Research 